\title{
Properties of Perfluoropolyethers for Space Applications
}

William R. Jones, Jr.

Lewis Research Center

Cleveland, Ohio

Prepared for the

ASME/STLE Tribology Conference

cosponsored by the American Society of Mechanical Engineers

and the Society of Tribologists and Lubrication Engineers

Lahaina, Hawaii, October 16-19, 1994

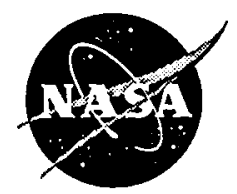

National Aeronautics and Space Administration Lewis Research Center Cleveland, Ohio 44135

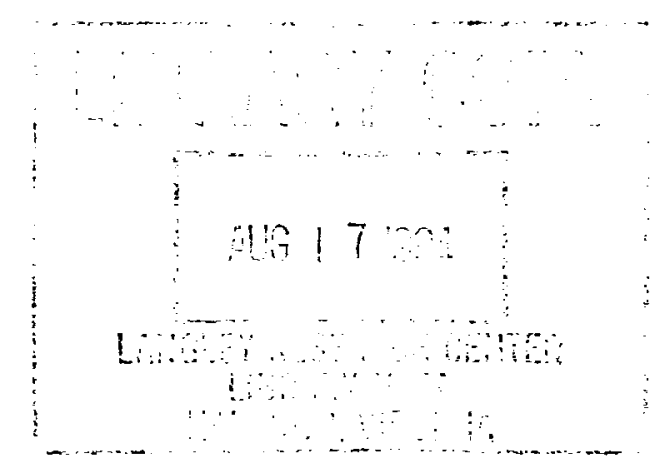




\title{
PROPERTIES OF PERFLUOROPOLYETHERS \\ FOR SPACE APPLICATIONS
}

\author{
William R. Jones, Jr. \\ National Aeronautics and Space Administration \\ Lewis Research Center \\ Cleveland, Ohio 44135
}

\begin{abstract}
$\underline{\text { Abstract }}$
The perfluoropolyether (PFPE) class of liquid lubricants has been used for space applications for over two decades. At first, these fluids performed satisfactorily as early spacecraft placed few demands on their performance. However, as other spacecraft components have become more reliable and lifetimes have been extended, PFPE lubricant deficiencies have been exposed. Therefore, the objective of this paper is to review the PFPE properties that are important for successful long term operation in space.
\end{abstract}

\section{Introduction}

The purpose of lubrication is to separate surfaces in relative motion by a material which has a low resistance to shear so that the surfaces do not sustain major damage. This material can be a variety of different species (e.g., adsorbed gases, reaction films, liquids, solid lubricants, etc.).

Depending on the type of film and its thickness, a number of lubrication regimes can be identified. A classical way of depicting these regimes is by use of the Stribeck curve (Fig. 1). Stribeck (1) performed comprehensive experiments on journal bearings around 1900. He measured the coefficient of friction as a function of load, speed, and temperature. Some years later, Hersey (2) performed similar experiments and devised a plotting format based on 
a dimensionless parameter. The Stribeck curve takes the form of the coefficient of friction as a function of the viscosity $(\mathrm{Z})$, velocity $(\mathrm{N})$, and load $(\mathrm{P})$ parameter, $\mathrm{ZN} / \mathrm{P}$.

At high values of $Z N / P$ which occur at high speeds, at high viscosities and at low loads, the surfaces are completely separated by a thick $(>0.25 \mu \mathrm{m})$ lubricant film. This is the area of hydrodynamic lubrication where friction is determined by the rheology of the lubricant. For nonconformal, concentrated contacts where loads are high enough to cause elastic deformation of the surfaces and pressure-viscosity effects on the lubricant, another regime, elastohydrodynamic lubrication (EHL) can be identified. In this regime film thicknesses (h) may range from (0.025 to $1.25 \mu \mathrm{m})$.

As fluid film thickness becomes progressively thinner, surface interactions start taking place. This regime of increasing friction in which there is a combination of asperity interactions and fluid film effects is referred to as the mixed lubrication regime. Finally, at low values of $\mathrm{ZN} / \mathrm{P}$, one enters the realm of boundary lubrication. This regime is characterized by the following (3):

1. It is a highly complex regime involving metallurgy, surface topography, physical and chemical adsorption, corrosion, catalysis, and reaction kinetics.

2. The most important aspect of this regime is the formation of protective surface (reaction) films to minimize wear and surface damage. (For space mechanisms, AISI 440C steel is the most common bearing material)

3. The formation of these films is governed by the chemistry of both the film former as well as the steel surface and other environmental factors. 
4. The effectiveness of these films in minimizing wear is determined by their physical properties which include: shear strength, thickness, surface adhesion, film cohesion, melting point or decomposition temperature, and solubility.

The perfluoropolyether (PFPE) class of liquid lubricants has been in use for over 25 years for many spacecraft applications (4). These commercial products are made by polymerization of perfluorinated monomers. The first member of this class was made by CsF catalyzed polymerization of hexafluoropropene oxide (HFPO) yielding a series of branched polymers designated in this paper as $\mathrm{K}$ fluids (5). A similar polymer is produced by the UV catalyzed photo-oxidation of hexafluoropropene ( $\mathrm{Y}$ fluid) (6). A linear polymer ( $\mathrm{Z}$ fluid) is prepared by a similar process but utilizing tetrafluoroethylene (7). Finally, a fourth polymer (D fluid) is produced by polymerization of tetrafluorooxetane followed by direct fluorination (8). Formulae for these fluids appear in Table 1. Table 2 contains property data for some members of the PFPE class of lubricants.

In addition to these commercially available PFPE fluids, a new series of structures are being prepared by direct fluorination technology (9)-(11). Some of these structures appear in Table 3.

Of the above PFPE fluids, only $\mathrm{K}$ and $\mathrm{Z}$ fluids have been extensively used as liquid lubricants and greases for space applications (4). Recently, a D fluid has been life tested for use as a shutter mechanism lubricant for the solar and heliospheric mission (SOHO).

The objective of this paper is to review some of the properties of the PFPE class of lubricants that are important for long term operation in space. This is not intended to be an extensive review of all PFPE properties, only those related to space requirements. For 
example, thermal and thermal-oxidative stability properties important for terrestrial applications, (12)-(17) will not be covered. In addition, many other classes of liquid lubricants are being used in space. These classes will not be discussed since adequate reviews already exist (18).

\section{Perfluoropolyether Properties}

As indicated in the introduction, a liquid lubricant has to possess certain physical and chemical properties to function properly in a lubricated contact. These lubricants must possess the following attributes for consideration for a space application: vacuum stability (i.e. low vapor pressure), low tendency to creep, high viscosity index (i.e. wide liquid range), good elastohydrodynamic and boundary lubrication properties, optical transparency, and resistance to radiation and atomic oxygen.

\section{$\underline{\text { Volatility }}$}

Although labyrinth seals are extensively used in space mechanisms, lubricant loss can still be a problem for long term applications (7 to 30 years) (19). For a fixed temperature, and outlet area, lubricant loss is directly related to vapor pressure. For a similar viscosity range, the PFPE fluids ( $\mathrm{Z}$ and $\mathrm{K}$ fluids) are particularly good candidates compared to conventional lubricants (Fig. 2) (4). Vapor pressure data also appear in Table 2 (Knudsen method).

\section{Creep Behavior}

The tendency of a liquid lubricant to creep or migrate is inversely related to its surface tension. Therefore, the PFPE materials which have unusually low surface tensions $\left(\gamma_{\mathrm{LV}}, 17\right.$ to 25 dynes/cm at $20^{\circ} \mathrm{C}$ ) are more prone to creep than conventional fluids. However, these 
fluids can effectively be contained in bearing raceways by using low surface energy fluorocarbon barrier films on bearing lands (having critical surface energies of less than 11 dynes $/ \mathrm{cm})(20)$. However, PFPE fluids may dissolve these barrier films with prolonged contact (19).

\section{Viscosity-Temperature Properties}

Although liquid lubricated space applications do not involve wide temperature ranges, low temperatures (i.e., -10 to $-20^{\circ} \mathrm{C}$ ) are sometimes encountered. Therefore, low pour point fluids that retain low vapor pressure and reasonable viscosities at temperatures to 50 or $60^{\circ} \mathrm{C}$ are required. The viscosity-temperature slope of PFPE unbranched fluids is directly related to the carbon to oxygen ratio $(\mathrm{C} / \mathrm{O})$ in the polymer repeating unit, as shown in Fig. 3 (21). Here, the ASTM slope (based on ASTM method D 341-43) (22) is used for the correlation. The ASTM slope is obtained by physically measuring the slope of the kinematic viscositytemperature data plotted on charts from D 341-43. Therefore, high values of the ASTM slope indicate large changes of viscosity with temperature. This parameter is no longer used in the latest ASTM standard (D 341-77) (23). It is used here to simply show the qualitative differences between the various fluids.

In addition, branching, such as the trifluoromethyl pendant group in the $\mathrm{K}$ fluids, causes a deterioration in viscometric properties. Comparison of ASTM slopes for three commercial PFPE fluids appears in Fig. 4. Here the low $\mathrm{C} / \mathrm{O}$ ratio fluid, $\mathrm{Z}$, has the best viscometric properties. The $\mathrm{D}$ fluid, with a $\mathrm{C} / \mathrm{O}$ ratio of 3 , has intermediate properties, while the branched fluid, $\mathrm{K}$, has the highest ASTM slope. 


\section{Elastohydrodynamic Properties}

The operation of continuously rotating, medium to high speed bearings relies on the formation of an elastohydrodynamic (EHL) film. This regime was briefly described in the introduction. A more detailed description appears in ref. 24. The two physical properties of the lubricant that influence EHL film formation are: absolute viscosity $(\mu)$ and the pressureviscosity coefficient $(\alpha)$.

Viscosity is influenced by both molecular weight and structure. Except for low molecular weight fluids, $\alpha$ values are only related to structure (25). Pressure-viscosity coefficients can be measured directly with conventional high pressure viscometers (24)-(31) or indirectly from optical EHL experiments (23), (30)-(34). Conventional viscometry normally uses the Barus equation (35) for correlations.

$$
\mu_{p}=\mu_{0} e^{\alpha p}
$$

where $\mu_{\mathrm{p}}=$ absolute viscosity at pressure, $\mathrm{p}$.

$\mu_{0}=$ absolute viscosity at atmospheric pressure, and $\alpha_{-}=$constant (temperature dependent but pressure independent).

This implies that a plot of $\log \mu_{\mathrm{p}}$ versus $\mathrm{p}$ should yield a straight line of slope $\alpha$. Unfortunately, this simple relationship is seldom obeyed. The pressure-viscosity properties that are important in determining EHL film thickness occur in the contact inlet. Therefore, the slope of a secant drawn between atmospheric pressure and $0.07 \mathrm{GPa}$ is typically used.

Winer (26) has advocated the use of another pressure-viscosity parameter, the reciprocal asymptotic isoviscous pressure $\left(\alpha^{*}\right)$ based on work by Roelands (36). Pressure 
viscosity coefficients $\left(\alpha^{*}\right)(26)$ for three temperatures $\left(38,99\right.$, and $\left.149{ }^{\circ} \mathrm{C}\right)$ are tabulated in Table 4 for a $\mathrm{Z}$ fluid (Z-25) and a $\mathrm{K}$ fluid (143AB). Values for several other non-PFPE fluids are shown for comparison.

Figure 5 contains $\alpha$ values for the branched PFPE (143AB). Data obtained by conventional (low shear) pressure-viscosity measurements are denoted with open symbols. Indirect measurements from EHL experiments (effective $\alpha$ values) are shown with solid symbols. There is good agreement comparing the different sources as well as different measurement techniques. Figure 6 contains similar data for the unbranched PFPE (Z-25) as a function of temperature. Here, there is a definite grouping of the data with effective $\alpha$ values being substantially lower than values from conventional measurements.

Two possibilities exist for this discrepancy. First, inlet heating can occur, thus leading to lower viscosities, lower film thicknesses, and resulting in lower effective $\alpha$ values. The second possibility is a non-Newtonian shear thinning effect. Shear rates in EHL inlets can range from $10^{5}$ to $10^{7} \sec ^{-1}$ (32). However, the EHL measurements do represent actual film thicknesses that can be expected in practice.

From EHL theory, the greatest film thickness should be obtained with a PFPE fluid having the largest $\alpha$ value. However, for many applications, lubricants must perform over a wide temperature range. In this case, the EHL inlet viscosity can be the overriding factor if the temperature coefficient of viscosity is high. This can cause a cross-over in film thickness as a function of temperature as shown by Spikes et al., (25) in Fig. 7. However, for most space applications, bearing temperatures are typically in the range of $0^{\circ}$ to $+40^{\circ} \mathrm{C}$. Therefore, lubricants possessing high $\alpha$ values (i.e., $\mathrm{K}$ fluids) in this range would be 
preferred, when only considering EHL.

\section{Boundary Lubrication}

As described in the introduction, boundary lubrication is the regime where surfaces are not completely separated which results in continuous surface asperity interactions. The most important aspect of this regime is the formation of protective surface films to minimize wear and surface damage. The formation of these films is governed by the chemistry of both the film former as well as the contacting surfaces and other environmental factors.

Non-additive hydrocarbons, mineral oils and esters will react in a boundary contact to produce "friction polymer" (37). Except for electrical contacts, this material is beneficial but does represent loss of lubricant which requires replenishment. But these conventional lubricants are never required to act alone. Almost all are formulated with antiwear, anti corrosion, extreme pressure, or anti-oxidant additives to enhance their performance.

Contrast this with a PFPE boundary lubricant. Here we have a relatively inert, very pure fluid with no additives. If these fluids were totally inert, they should not provide any surface protection except for some fluid film effects (micro-EHL), removal of wear debris, and possibly some local cooling. Actually, in boundary contacts, PFPE fluids do react with bearing surfaces producing a series of corrosive gases which, in turn, react with existing surface oxides producing metal fluorides (36)-(40). These fluorides are effective solid lubricants which reduce friction and wear (38).

Unfortunately, these fluorides are also strong Lewis acids (electron acceptors) which readily attack and decompose PFPE molecules (40)-(42). This causes the production of more reactive species which, in turn, produce more surface fluoride, resulting in an auto catalytic 
reaction. Therefore, the very reaction that allows the use of pure PFPE fluids in boundary contacts, eventually leads to their destruction and accompanying bearing failure. Of course, the progression of this mechanism is highly dependent on the local contact conditions (i.e., degree of passivation, type and thickness of surface oxide, amount of surface contaminants, temperature, load, speed, etc.).

A preliminary boundary lubrication study of three commercial PFPE fluids (43) under sliding conditions in air and vacuum has been conducted with a vacuum four-ball apparatus using 440C stainless steel bearing balls (43). Wear rates for these fluids appear in Fig. 8. The following order of lubricant lifetimes was obtained: $K$ fluid $\cong Z$ fluid $>D$ fluid (air) and $\mathrm{K}$ fluid $\cong \mathrm{D}$ fluid $\gg \mathrm{Z}$ fluid (vacuum) (Fig. 8). Although D fluid has no space heritage, both $\mathrm{K}$ and $\mathrm{Z}$ fluids have been used extensively and successfully. Space experience has indicated that, in general, $\mathrm{K}$ fluid yields longer lifetimes than $\mathrm{Z}$ fluids for similar applications. Therefore, the vacuum 4-ball results correlate with results from space experience.

A classical way of representing wear as a function of lubricant reactivity is shown in Fig. 9 (44). The optimum lubricant reactivity (or additive concentration or additive reactivity) is determined by the severity of the contact conditions. The greater the severity, the greater the required reactivity to bring about a proper balance. Obviously, for any particular system, one would like to be at the minimum of the curve. Normally, this minimum is perturbed by the presence and concentration of lubricant additives. However, as previously indicated, boundary additives are not yet available for PFPE fluids. However, active research (45)-(47) is now taking place in this arena. 


\section{Optical Characteristics}

There is always the concern that liquid lubricants used in space mechanisms may contaminate sensitive optical components (mirrors, windows, etc.) and render certain measurements useless. Although great care is taken to minimize this problem, the possibility still exists. Therefore, lubricants that are optically transparent in the various sensor wavelength regions are obviously preferred. Many of these regions are in the infrared region. Since PFPE lubricants do not contain hydrogen, they are relatively transparent over most of this region (from 1400 to $4800 \mathrm{~cm}^{-1}$ ) (Fig. 10) for a $\mathrm{K}$ fluid. Infrared spectral regions of interest for two Earth Observation Satellites [CERES (Clouds and the Earth's Radiant Energy System)and MODIS-N (Moderate Resolution Imaging Spectrometer-Nadir) ] are also shown. $\underline{\text { Radiation Resistance }}$

PFPE fluids are susceptible to degradation from low energy electrons (48), high energy electrons (49) and ion beams (50). Mori and Morales (51) have reported the degradation of several PFPE fluids (D fluid, S200, Z fluid, Z-25, and $\mathrm{K}$ fluid, 16256) by $\mathrm{X}$-rays. X-rays were generated by an $\mathrm{Al} \mathrm{K \alpha}$ source in a commercial $\mathrm{x}$-ray photoelectron spectrometer (XPS). Thick PFPE layers were swabbed onto $440 \mathrm{C}$ steel substrates and exposed to $\mathrm{x}$-rays for three hours. Degradation was measured by changes in chamber pressure as a function of time. Pressure changes for three fluids appear in Fig. 11. First order rate constants calculated from these slopes indicated that $\mathrm{Z}$ fluid (Z-25) and $\mathrm{K}$ fluid (16256) had degradation rates approximately twice that of D fluid (S200). These data indicate that PFPE materials are very susceptible to degradation by X-Ray irradiation. 


\section{Resistance to Atomic Oxygen}

In low earth orbit (LEO), the principle chemical species is neutral atomic oxygen. In LEO, $4.25 \mathrm{eV}$ atomic oxygen will impact spacecraft surfaces. Although space mechanism liquid lubricants are not directly exposed to this particle flux, it has been shown by Gulino and Coles (52) that of several candidate radiator fluids, the PFPE class was less affected by atomic oxygen than silicone based materials. However, $\mathrm{K}$ fluid (143AB) and $\mathrm{Z}$ fluid (Z-25) did show small weight losses (Fig. 12) as a function of oxygen plasma exposure time.

\section{Conclusions}

The following conclusions can be stated for the use of perfluoropolyether (PFPE) liquid lubricants for space applications.

1. The PFPE lubricant class can still provide adequate performance for less demanding space applications (i.e., pure EHL or low load, low cycle boundary contacts).

2. For more demanding applications (i.e., high load, high cycle or for contacts having high sliding components), additive technology (antiwear, EP, anti corrosion, anti degradation) will be mandatory.

3. Although active research is now taking place for the development of PFPE boundary additive formulations, they are not yet available commercially.

4. In the interim, the use of alternative bearing materials (i.e., ceramics) or steel surface treatments (i.e., ion implantation, phosphating, acid passivation) will be necessary for extension of lifetimes. 


\section{$\underline{\text { References }}$}

1. Stribeck, R.: "Characteristics of Plain and Roller Bearings," Ziet. V.D.I., 46 (1902).

2. Hersey, M.D.: "The Laws of Lubrication of Horizontal Journal Bearings," J. Wash. Acad. Sci. 4, pp. 542-552, (1914).

3. Godfrey, D., "Review of Usefulness of New Surface Analysis Instruments in Understanding Boundary Lubrication," Fundamentals of Tribology, ed. by N.P. Suh and N. Saka, MT Press, pp. 945-967, (1980).

4. Conley, P.L., and Bohner, J.J., "Experience with Synthetic Fluorinated Fluid Lubricants," 24th Aerospace Mechanisms Symposium, NASA CP-3062, pp. 213-230, (April 18-20, 1990).

5. Gumprecht, W.H., "PR-143--A New Class of High-Temperature Fluids," ASLE Trans., 9, pp. 24-30, (1966).

6. Sianesi, D., Zamboni, V., Fontanelli, R., and Binaghi, M., "Perfluoropolyethers. Their Physical Properties and Behavior at High and Low Temperatures," Wear, 18, pp. 85-100, (1971).

7. Sianesi, D., Pasetti, A., Fontanelli, R., and Bernardi, G.C., "Perfluoropolyethers by Photooxidation of Fluoroolefins," Chim Ind. (Milan) 55, pp. 208-221, (1973).

8. Ohsaka, Y., "Recent Advances in Synthetic Lubricating Oils. (8). Perfluorinated Polyethers," Petrotech (Tokyo), 8, 9, pp. 840-843, (1985).

9. Lagow, R.J., and Margrave, J.L., "Direct Fluorination: A "New" Approach to Fluorine Chemistry," In Progress in Inorganic Chemistry, 26, Lippard, S.J., Ed., Wiley, New York, pp. 162-210, (1979).

10. Jones, W.R., Bierschenk, T.R., Juhlke, T.J., Kawa, H., and Lagow, R.J., "Improved Perfluoroalkyl Ether Fluid Development," Ind. Eng. Chem. Res., 26, pp. 1930-1935, (1987).

11. Bierschenk, T.R., Kawa, H., Juhlke, T.J., and Lagow, R.J., "The Development of New, Low-Cost Perfluoroalkylether Fluids with Excellent Low and High-Temperature Properties," NASA CR-182155, (May 1988), available from NTIS, Springfield, VA, 22161.

12. Snyder, C.E., Jr., and Dolle, R.E., "Development of Polyperfluoroalkylethers as High Temperature Lubricants and Hydraulic Fluids," ASLE Trans., 19, pp. 171-180, (1976). 
13. Snyder, C.E., Jr., Gschwender, L.J., and Tamborski, C., "Linear Polyperfluoroalkylether-Based Wide-Liquid-Range High-Temperature Fluids and Lubricants," Lubr. Eng., 37, pp. 344-349, (1981).

14. Snyder, C.E., Jr., Gschwender, L.J., and Campbell, W.B., "Development and Mechanical Evaluation of Nonflammable Aerospace $\left(-54^{\circ} \mathrm{C}\right.$ to $\left.135^{\circ} \mathrm{C}\right)$ Hydraulic Fluids," Lubr. Eng. 38, pp. 41-51, (1982).

15. Paciorek, K.J.L., Kratzer, R.H., Kaufman, J., and Nakahara, J.H., "Thermal Oxidative Studies of Poly(hexafluoropropene Oxide Fluids," J. Appl. Poly. Sci., 24, pp. 1397-1411, (1979).

16. Jones, W.R., Jr., Kazimiera, J.L., Paciorek, T., Ito, I., and Kratzer, R.H., "Thermal Oxidative Degradation Reactions of Linear Perfluoroalkyl Ethers," I\&EC Prod. Res. Dev., 22, pp. 166-170, (1983).

17. Jones, W.R., Jr. Paciorek, K.J., Harris, D.H., Smythe, M.E., Nakahara, J.H., and Kratzer, R.H., "The Effects of Metals and Inhibitors on Thermal Oxidative Degradation Reactions of Unbranched Perfluoroalkyl Ethers," I\&EC Prod. Res. Dev., 24, pp. 417-420, (1985).

18. Zaretsky, E., "Liquid Lubrication in Space," Tribology International, 23, 2, pp. 75-93, (1990).

19. Hilton, M.R. and Fleischauer, P.D.: "Lubricants for High-vacuum Applications," Aerospace Report No. TR-0091 (6945-03)-6, (1993), available from NTIS, Springfield, VA, 22161.

20. Kinzig, B.J. and Ravner, H., "Factors Contributing to the Properties of Fluoropolymer Barrier Films," ASLE Trans., 21, pp. 291-298, (1978).

21. Jones, W.R., Jr., Bierschenk, T.R., Juhlke, T.J., Kawa, H., and Lagow, R.J., "The Preparation of New Perfluoroether Fluids Exhibiting Excellent Thermal-Oxidative Stabilities," NASA TM-87284, (1986), available from NTIS, Springfield, VA, 22161.

22. ASTM Standard D-341-43, "Viscosity-Temperature Charts for Liquid Petroleum Products."

23. ASTM Standard D-341-77 (Reapproved 1982), "Viscosity-Temperature Charts for Liquid Petroleum Products."

24. Wedeven, L.D., "What is EHD ?," Lubr. Engr., 31, 6, pp. 291-296, (1975). 
25. Spikes, H.A., Cann, P., and Caporiccio, G., "Elastohydrodynamic Film Thickness Measurements of Perfluoropolyether Fluids," J. Syn. Lubr., 1, 1, pp. 73-86, (1984).

26. Jones, W.R., Jr., Johnson, R.L., Winer, W.O., and Sanborn, D. M.: "Pressure-Viscosity Measurements for Several Lubricants to $5.5 \times 10^{8}$ Newtons per Square Meter

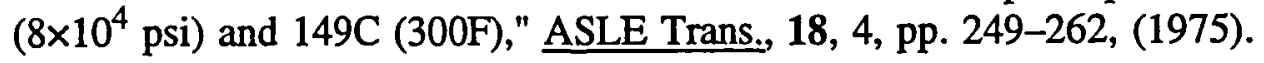

27. Tanaka, Y., Nojiri, N., Ohta, K., Kubota, H., and Makita, T., "Density and Viscosity of Linear Perfluoropolyethers under High Pressures," Int. J. of Thermophysics, 10, 4, pp. 857-870, (1989).

28. Vergne, P. and Reynaud, P., "High Pressure Behavior of Space Liquid Lubricants," Trib. 2000, 2, paper No. 19.12, W.J. Bartz, Ed., Tech. Acad. Esslingen, Publ.; Ostfildern, Germany (1992).

29. Alper, T., Barlow, A.J., Gray, R.W., Kim, M.G., McLachlan, R.J. and Lamb, J., "Viscous, Viscoelastic and Dielectric Properties of a Perfluorinated Polymer. Krytox 143 AB," J.C.S. Faraday II, 76, pp. 205-216, (1980).

30. Cantow, M.J.R., Barrall II, E.M., Wolf, B.A. and Geerissen, H., "Temperature and Pressure Dependence of the Viscosities of Perfluoropolyether Fluids," J. Poly Sci. Part B: Poly. Phy., 25, pp. 603-609, (1987).

31. Corti, C. and Savelli, P., "Synthetics Profile: Perfluoropolyether Lubricants," $\underline{\text { J. Syn. }}$ Lub., 9, 4, pp. 311-330, (1993).

32. Foord, C.A., Hamman, W.C., and Cameron, A., "Evaluation of Lubricants Using Optical Elastohydrodynamics," ASLE Trans., 11, 1, pp. 31-43, (1968).

33. Westlake, F.J. and Cameron, A., "Optical Elastohydrodynamic Fluid Testing," ASLE Trans., 15, 2, pp. 81-95, (1972).

34. Aderin, M., Johnston, G.J., Spikes, H.A., and Caporiccio, G., "The Elastohydrodynamic Properties of Some Advanced Non Hydrocarbon-Based Lubricants," Lubr. Engr., 48, 8, pp. 633-638, (1992).

35. Barus, C., "Isothermals, Isopiestics, and Isometrics Relative to Viscosity,": Am. J. Sci., 45, pp. 87-96, (1893).

36. Roelands, C.H.A., "Correlation Aspects of the Viscosity-Temperature-Pressure Relationship of Lubricating Oils," O.P. Books Program, University Microfilm, Ann Arbor, Michigan (1966). 
37. Lauer, J.L. and Jones, W.R., "Friction Polymers," ASLE Special Publ. SP-21, Tribology and Mechanics of Magnet Storage Systems, III, pp. 14-23, (1987).

38. Mori, S. and Morales, W., "Tribological Reactions of Perfluoroalkyl Polyether Oils with Stainless Steel Under Ultrahigh Vacuum Conditions at Room Temperatures," Wear, 132, pp. 111-121, (1989).

39. Carré, D.J., "Perfluoropolyalkylether Oil Degradation: Interference of $\mathrm{FeF}_{3}$ Formation on Steel Surfaces Under boundary Conditions," ASLE Trans., 29, 2, pp. 121-125, (1986).

40. Herrera-Fierro, P., Jones, W.R., and Pepper, S.V., "Interfacial Chemistry of a Perfluoropolyether Lubricant Studied by XPS and TDS," J. Vac. Sci. Tech. A., 11(2), pp. 354-367, (1993).

41. Carré, D.J., and Markowitz, J.A., "The Reaction of Perfluoropolyalkylether Oil with $\mathrm{FeF}_{3}, \mathrm{AlF}_{3}$, and $\mathrm{AlCl}_{3}$ at Elevated Temperatures," ASLE Trans., 28, 1, pp. 40-46, (1985).

42. Kasai, P.H., "Perfluoropolyethers: Intramolecular Disporportionation," Macromolecules, 25, pp. 6791-6799, (1992).

43. Masuko, M., Jones, W.R. Jr., Helmick, L.S., "Tribological Characteristics of Perfluoropolyether Liquid Lubricants under Sliding Conditions in High Vacuum," NASA TM-106257, (1993), available from NTIS, Springfield, VA, 22161.

44. Rowe, C.N., "Wear-Corrosion and Erosion," Interdisciplinary Approach to Liquid Lubricant Technology, NASA SP-318, pp. 527-568, (1973), available from NTIS, Springfield, VA, 22161.

45. Sharma, S.K., Gschwender, L.J. and Snyder, C.E., Jr., "Development of a Soluble Lubricity Additive for Perfluoropolyalkylether Fluids," Journal of Synthetic Lubrication, 7, 1, pp. 15-23, (1990).

46. Gschwender, L.J., Snyder, C.E., Jr., and Fultz, G.W., "Soluble Additives for Perfluoropolyalkylether Liquid Lubricants," Lubr. Engr. 49, 9, pp. 702-708, (1993).

47. Williams, J.R., Feuchter, D., and Jones, W.R., Jr., "Development and Preliminary Evaluation of Aryl Ester Boundary Additives for Perfluoropolyethers," NASA TM-108275, (1994), available from NTIS, Springfield, VA, 22161.

48. D'Anna, E., et al., "Fragmentation Spectra and Appearance Potentials of Vacuum Pump Fluids Determined by Electron Impact Mass Spectrometry," J. Vac. Sci. Tech. A, 5, 6, pp. 3436-3441, (1987). 
49. Pacansky, J., Waltman, R.J., and Wang, C., "Irradiation of Poly(perfluoropropylene oxide) by a 175-kV Electron Beam: The Formation and Hydrolysis of Acid Fluoride Groups," J. Fluorine Chem. 32, 3, pp. 283-297, (1986).

50. Coburn, J.W., and Winters, H.F., "Ion-Induced Volatilization (IIV): A Method for Quantitative Measurement of the Amounts of Perfluoropolyether Lubricant on a Particulate Disk Surface and in the Media Porosity," J. Appl. Phys., 60, 9, pp. 3309-3314, (1986).

51. Mori, S. and Morales, W., "Degradation and Crosslinking of Perfluoroalkyl Polyethers Under X-ray Irradiation in Ultrahigh Vacuum," NASA TP-2910, (1989), available NTIS, Springfield, VA, 22161.

52. Gulino, D.A. and Coles, C.E., "Oxygen Plasma Effects on Several Liquid Droplet Radiator Fluids," J. Spacecraft and Rockets, 25, 2, pp. 99-101, (1988). 
Table I. Names and Primary Chemical Structures of Commercial PFPE Fluids

\begin{tabular}{|c|l|}
\hline Designation & \multicolumn{1}{|c|}{ Structure } \\
\hline $\mathrm{D}$ & $\mathrm{C}_{3} \mathrm{~F}_{7} \mathrm{O}\left(\mathrm{CF}_{2} \mathrm{CF}_{2} \mathrm{CF}_{2} \mathrm{O}\right)_{\mathrm{x}} \mathrm{C}_{2} \mathrm{~F}_{5}$ \\
$\mathrm{~K}$ & $\mathrm{C}_{3} \mathrm{~F}_{7} \mathrm{O}\left[\mathrm{CF}\left(\mathrm{CF}_{3}\right) \mathrm{CF}_{2} \mathrm{O}\right]_{\mathrm{x}} \mathrm{C}_{2} \mathrm{~F}_{5}$ \\
$\mathrm{Y}$ & $\mathrm{C}_{3} \mathrm{~F}_{7} \mathrm{O}\left[\mathrm{CF}\left(\mathrm{CF}_{3}\right) \mathrm{CF}_{2} \mathrm{O}\right]_{\mathrm{x}}\left(\mathrm{CF}_{2} \mathrm{O}\right)_{\mathrm{y}} \mathrm{C}_{2} \mathrm{~F}_{5}$ \\
$\mathrm{Z}$ & $\mathrm{CF}_{3} \mathrm{O}\left(\mathrm{CF}_{2} \mathrm{CF}_{2} \mathrm{O}\right)_{\mathrm{x}}\left(\mathrm{CF}_{2} \mathrm{O}\right)_{\mathrm{y}} \mathrm{CF}_{3}$ \\
\hline
\end{tabular}

Table II. Physical Properties of Four Commercial PFPE Lubricants

\begin{tabular}{|c|c|c|c|c|c|c||}
\hline Lubricant & $\begin{array}{c}\text { Average } \\
\end{array}$ & $\begin{array}{c}\text { Molecular } \\
\text { Weight }\end{array}$ & $\begin{array}{c}\text { Viscosity } \\
\text { at } 200^{\circ} \mathrm{C}, \\
\mathrm{cSt}\end{array}$ & $\begin{array}{c}\text { Viscosity } \\
\text { Index }\end{array}$ & \multirow{2}{*}{$\begin{array}{c}\text { Pour } \\
\text { Point, }{ }^{\circ} \mathrm{C}\end{array}$} & \multicolumn{2}{|c|}{ Vapor Pressure, Pascal } \\
\cline { 5 - 8 } & & & & & at $20^{\circ} \mathrm{C}$ & at $100^{\circ} \mathrm{C}$ \\
\hline $\mathrm{Z}(\mathrm{Z}-25)$ & 9500 & 255 & 355 & -66 & $3.9 \times 10^{-10}$ & $1.3 \times 10^{-6}$ \\
\hline $\mathrm{K}(143 \mathrm{AB})$ & 3700 & 230 & 113 & -40 & $2.0 \times 10^{-4}$ & $4 \times 10^{-2}$ \\
\hline $\mathrm{K}(143 \mathrm{AC})$ & 6250 & 800 & 134 & -35 & $2.7 \times 10^{-6}$ & $1.1 \times 10^{-3}$ \\
\hline $\mathrm{D}(\mathrm{S}-200)$ & 8400 & 500 & 210 & -53 & $1.3 \times 10^{-8}$ & $1.3 \times 10^{-5}$ \\
\hline
\end{tabular}


Table III. Names and Primary Chemical Structures of Custom Synthesized PFPE Fluids

\begin{tabular}{||l|l||}
\hline \multicolumn{1}{|c|}{ Perfluoropoly- } & \multicolumn{1}{|c|}{ Structure } \\
\hline (methylene oxide) (PMO) & $\mathrm{CF}_{3} \mathrm{O}\left(\mathrm{CF}_{2} \mathrm{O}\right)_{\mathrm{x}} \mathrm{CF}_{3}$ \\
(ethylene oxide) (PEO) & $\mathrm{CF}_{3} \mathrm{O}\left(\mathrm{CF}_{2} \mathrm{CF}_{2} \mathrm{O}\right)_{\mathrm{x}} \mathrm{CF}_{3}$ \\
(dioxolane) (DIOX) & $\mathrm{CF}_{3} \mathrm{O}\left(\mathrm{CF}_{2} \mathrm{CF}_{2} \mathrm{OCF}_{2} \mathrm{O}\right)_{\mathrm{x}} \mathrm{CF}_{3}$ \\
(trioxocane) (TRIOX) & $\mathrm{CF}_{3} \mathrm{O}\left[\left(\mathrm{CF}_{2} \mathrm{CF}_{2} \mathrm{O}\right)_{2} \mathrm{CF}_{2} \mathrm{O}_{\mathrm{x}} \mathrm{CF}_{3}\right.$ \\
\hline
\end{tabular}

Table IV. Pressure Viscosity Coefficients at Three Temperatures $\alpha^{*}, \mathrm{~Pa}^{-1} \times 10^{8}$ for Several Lubricants (Ref. 26)

\begin{tabular}{|l|c|c|c||}
\hline & $38 \mathrm{C}$ & $99 \mathrm{C}$ & $149 \mathrm{C}$ \\
\hline Ester & 1.3 & 1.0 & 0.85 \\
\hline Synthetic Paraffin & 1.8 & 1.5 & 1.1 \\
\hline Z Fluid (Z-25) & 1.8 & 1.5 & 1.3 (Extrapolated) \\
\hline $\begin{array}{l}\text { Naphthenic } \\
\text { Mineral Oil }\end{array}$ & 2.5 & 1.5 & 1.3 \\
\hline Traction Fluid & 3.1 & 1.7 & 0.94 \\
\hline K Fluid (143AB) & 4.2 & 3.2 & 3.0 \\
\hline
\end{tabular}




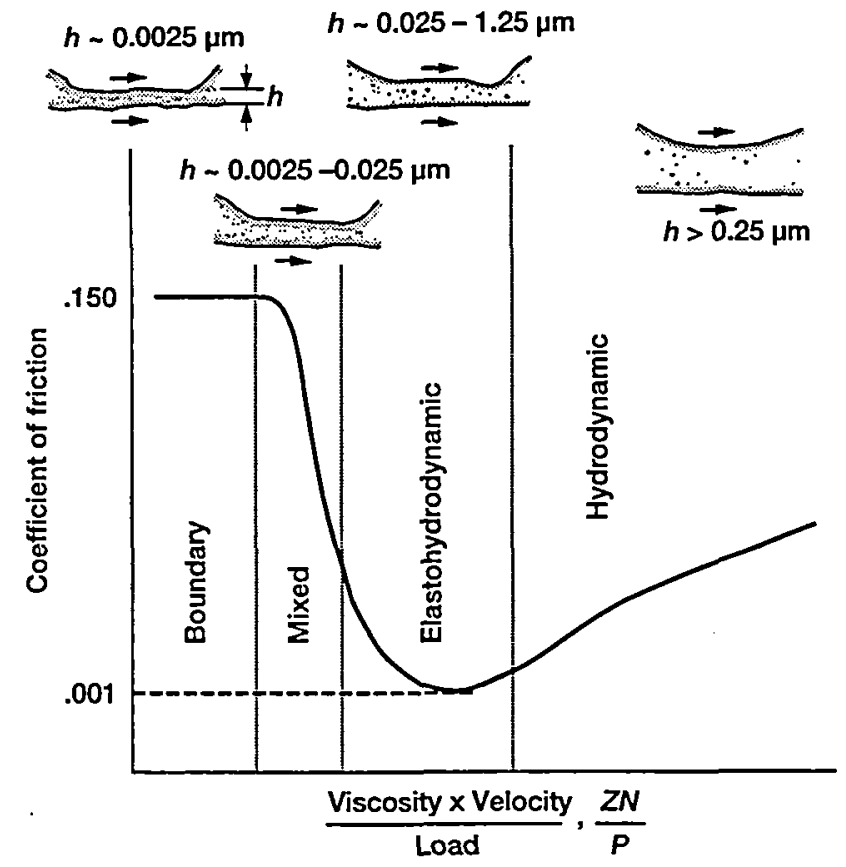

Figure 1.-Coefficient of friction as a function of viscosityvelocity-load parameter (Stribeck curve)(Ref. 1).

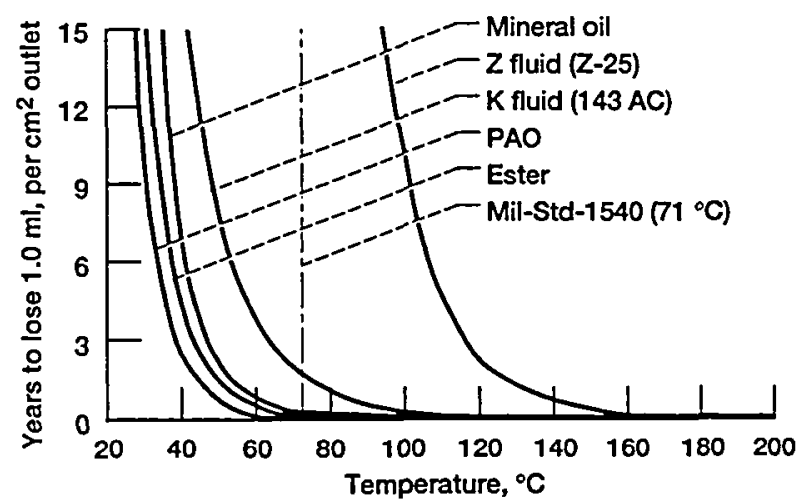

Figure 2.-Relative evaporation of aerospace lubricants (Ref. 4).

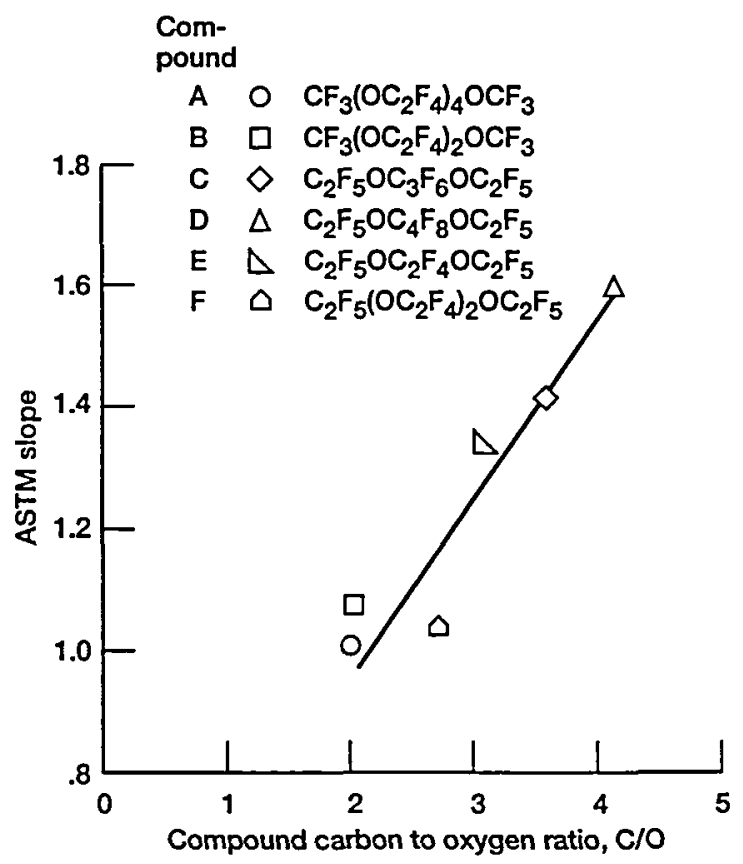

Figure 3.-Viscosity-temperature slope (ASTM D 341-43) as a function of compound carbon to oxygen ratio $(\mathrm{C} / \mathrm{O})$ for a series of unbranched perfluoroalkylethers (Ref. 21).

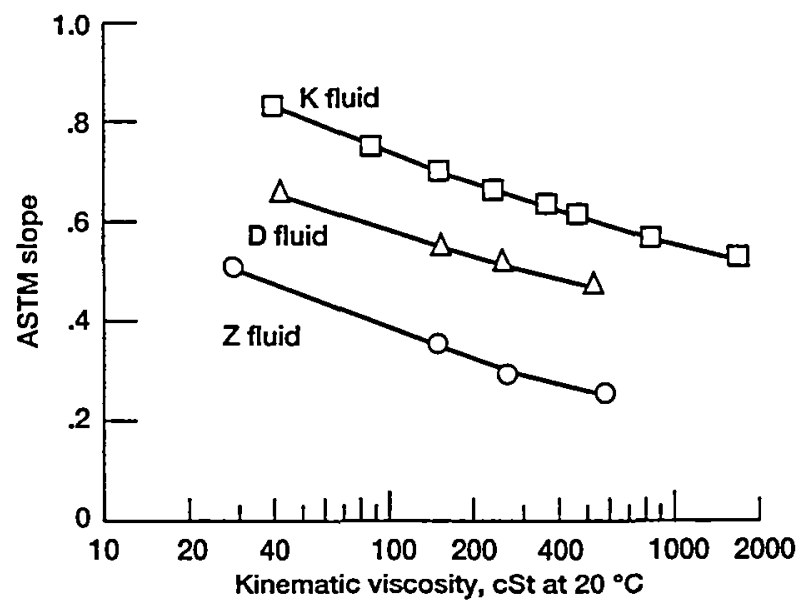

Figure 4.-Viscosity-temperature slope (ASTM D 341-43) as a function of kinematic viscosity at $20^{\circ} \mathrm{C}$ for $\mathrm{K}, \mathrm{D}$, and $Z$ fluids (Ref. 21). 


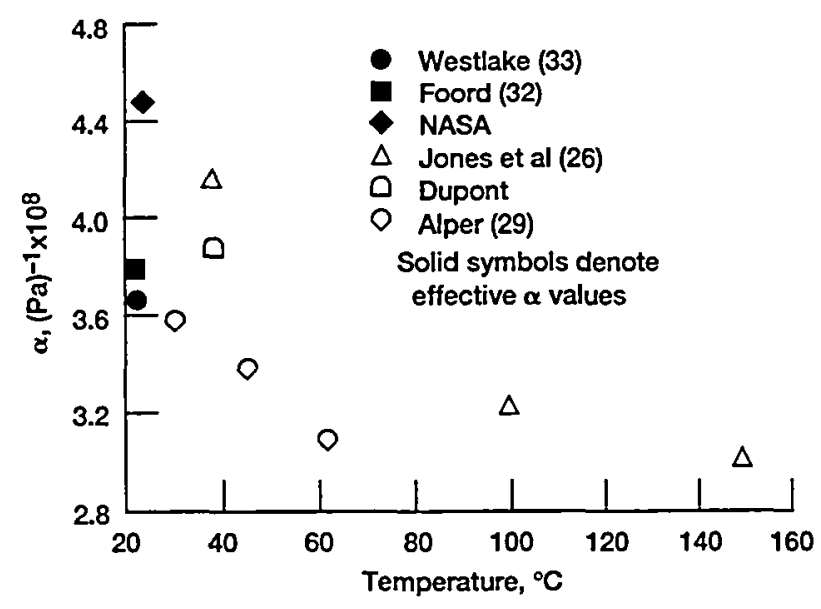

Figure 5.-Pressure-viscosity coefficients for $K$ fluid (143 AB) as a function of temperature.

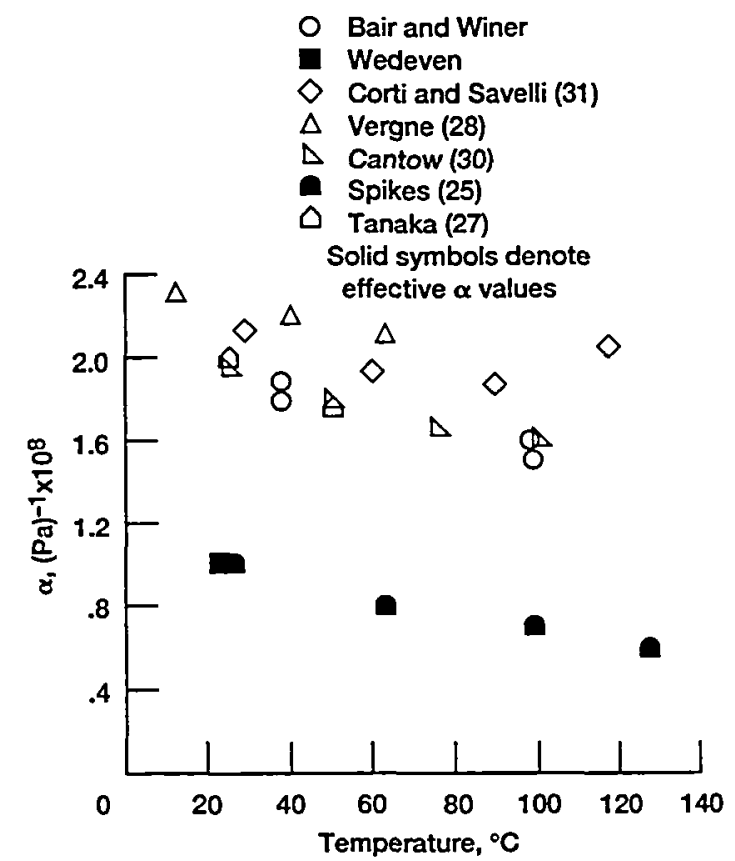

Figure 6.-Pressure-viscosity coefficients for $Z$ fluid $(\mathrm{Z}-25)$ as a function of temperature.

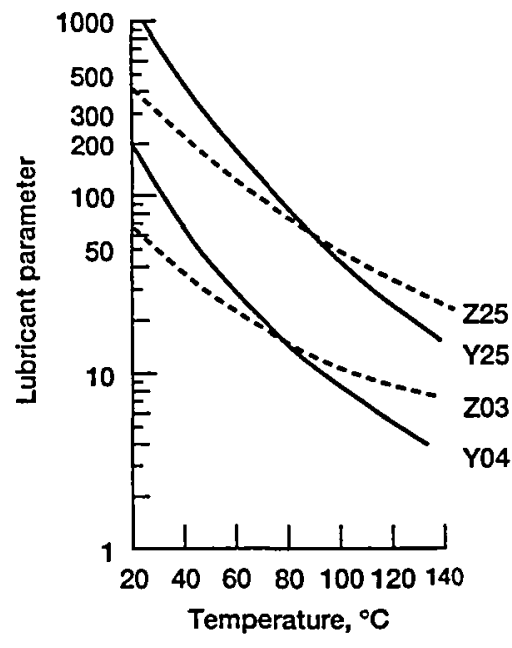

Figure 7.-Lubricant parameters for Fomblin $Y$ and $Z$ fluids (Ref. 25).

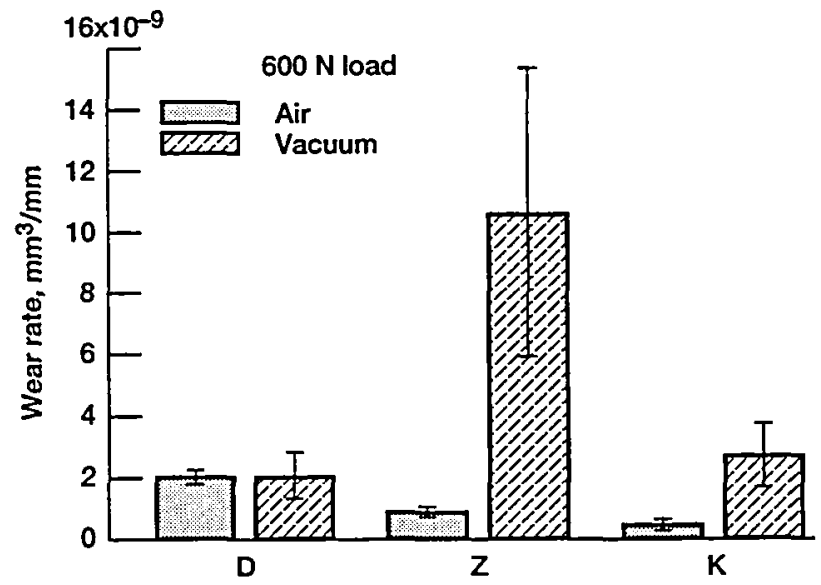

Figure 8.-Comparison of wear rates in air and vacuum for $K, Z$, and $D$ fluids in a vacuum four-ball apparatus using $400 \mathrm{C}$ stainless steel bearing balls (Ref. 43). 


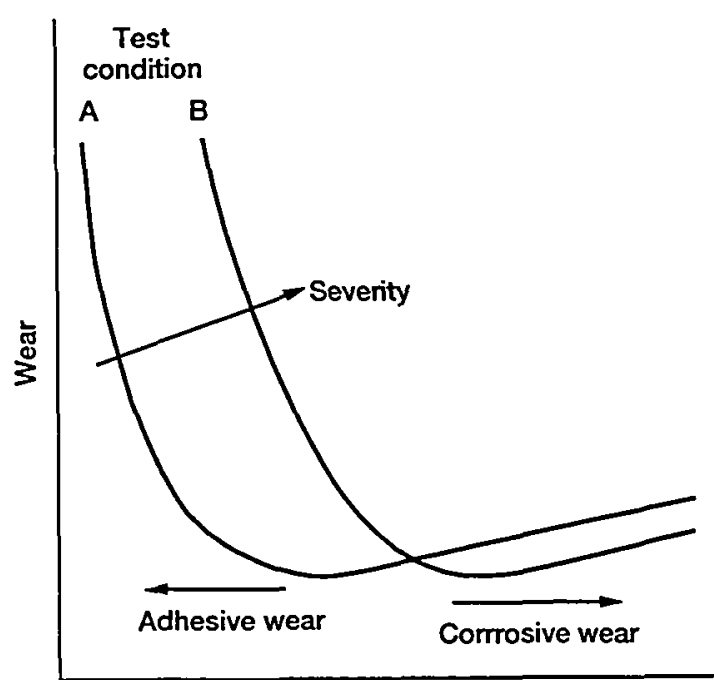

Lubricant or additive reactivity

Figure 9.-Relationship between wear and lubricant or additive reactivity (Ref. 44 ).

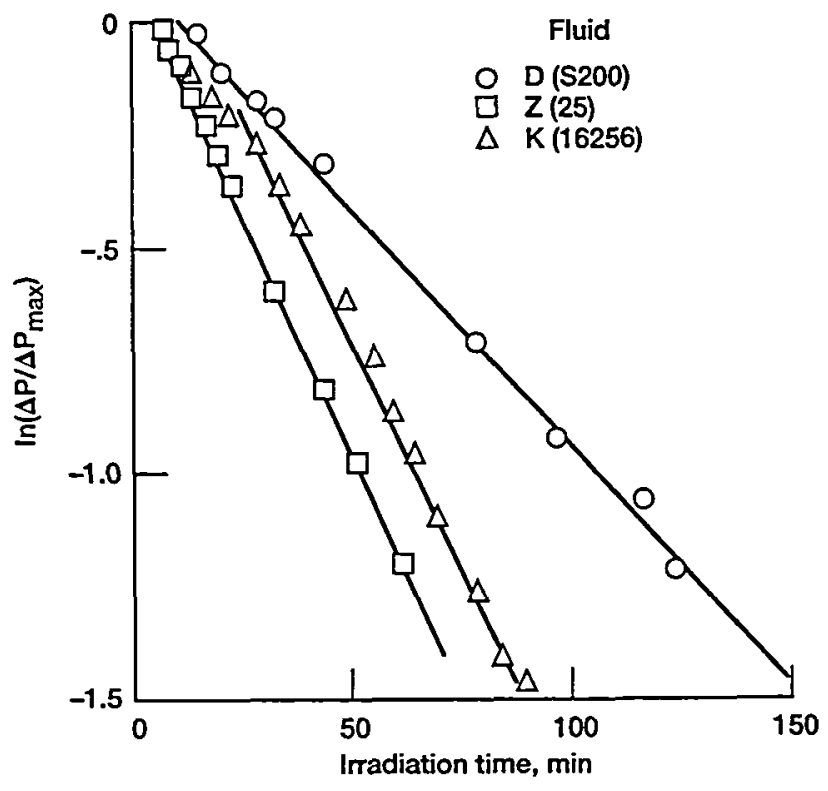

Figure 11.-Semilogarithmic relation of pressure change with irradiation time. Substrate, $440 \mathrm{C}$ stainless steel (Ref. 51).

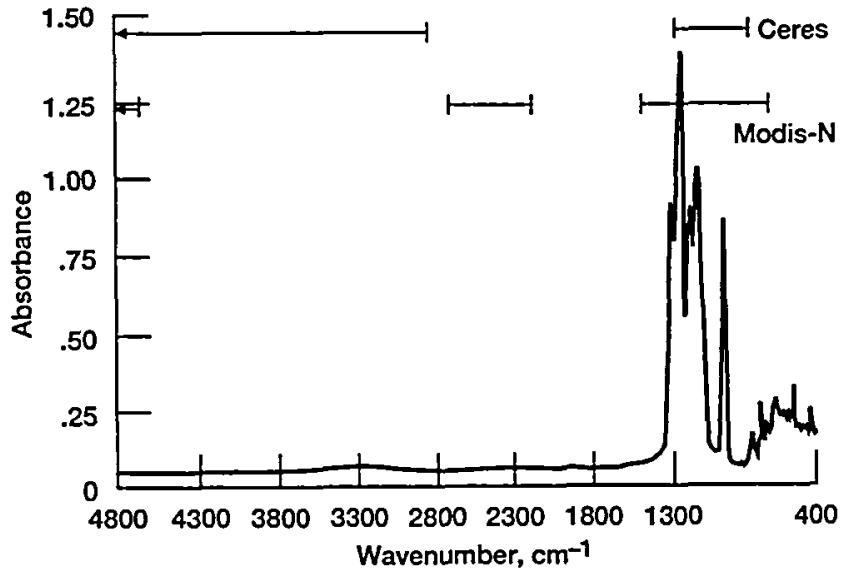

Figure 10.- Infrared spectrum of $K$ fluid and spectral bands sensed by two earth observation satellites (Ceres and Modis-N).

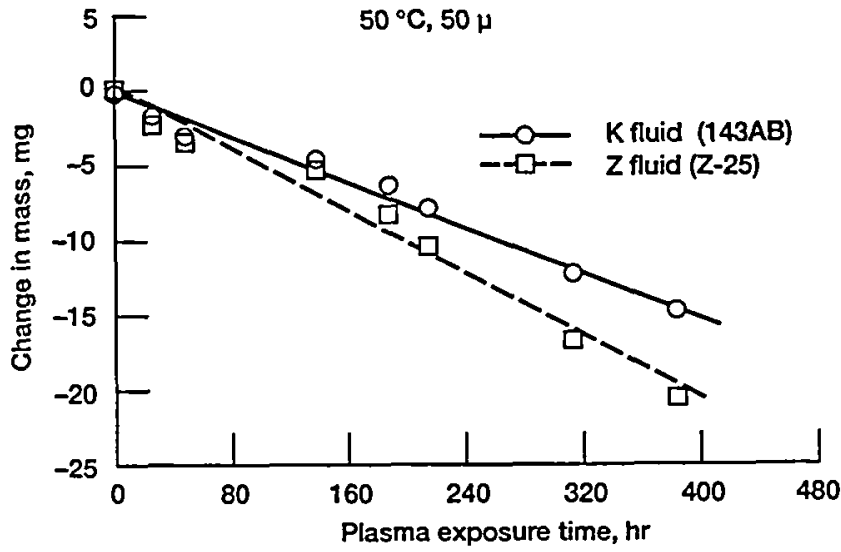

Figure 12.-Mass change as a function of oxygen plasma exposure time (Ref. 52). 
Public reporting burden for this collection of information is estimated to average 1 hour per response, including the time for reviewing instructions, searching existing data sources, gathering and maintaining the data needed, and completing and reviewing the collection of information. Send comments regarding this burden estimate or any other aspect of this collection of information, including suggestions for reducing this burden, to Washington Headquarters Services, Directorate for Information Operations and Reports, 1215 Jefferson Davis Highway, Suite 1204, Arlington, VA 22202-4302, and to the Office of Management and Budget, Paperwork Reduction Project (0704-0188), Washington, DC 20503.
1. AGENCY USE ONLY (Leave blank)
2. REPORT DATE
June 1994
3. REPORT TYPE AND DATES COVERED
Technical Memorandum

4. TITLE AND SUBTITLE

Properties of Perfluoropolyethers for Space Applications

6. AUTHOR(S)

WU-233-02-0D

William R. Jones, Jr.

7. PERFORMING ORGANIZATION NAME(S) AND ADDRESS(ES)

National Aeronautics and Space Administration

Lewis Research Center

Cleveland, Ohio 44135-3191

9. SPONSORINGMONITORING AGENCY NAME(S) AND ADDRESS(ES)

National Aeronautics and Space Administration

Washington, D.C. 20546-0001
5. FUNDING NUMBERS 
National Aeronautics and

Space Administration

Lewis Research Center

21000 Brookpark Rd.

Cleveland, OH 44135-3191

Officlal Business

Penalty for Private Use $\$ 300$

POSTMASTER: If Undeliverable - Do Not Return

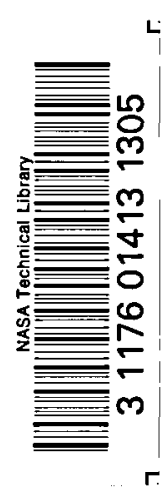

